\title{
The Effects of Outside- in Versus Inside-out Transobturator Tapes, for Stress Urinary Incontinence, on Sexual Function and Quality of Life: A Prospective Study
}

\author{
(1)Bülent ARICI, ${ }^{a}$ \\ - 1 Çiğdem PULATOĞLU, ${ }^{\circ}$ \\ (1) Osman TEMIZKAN, ${ }^{a}$ \\ DOzan DOĞAN, ${ }^{c}$ \\ (-) Osman AŞICIOĞLU, d \\ DFaruk ABIKE ${ }^{\mathrm{e}}$ \\ ${ }^{a}$ Clinic of Gynecology and Obstetrics, \\ Acıbadem Altunizade Hospital, \\ 'Department of Gynecology and Obstetrics, \\ Health Sciences University, \\ Şişli Hamidiye Etfal Training and \\ Research Hospital, \\ ${ }^{d}$ Clinic of Gynecology and Obstetrics, \\ Kanuni Sultan Süleyman Training and \\ Research Hospital, \\ ${ }^{e}$ Clinic of Gynecology and Obstetrics, \\ Florance Nightingale Group, \\ İstanbul \\ ${ }^{b}$ Clinic of Gynecology and Obstetrics, \\ Bayburt Government Hospital, \\ Bayburt
}

Received: 18.05.2018

Received in revised form: 18.06.2018

Accepted: 19.06.2018

Available online: 31.08 .2018

Correspondence:

Ozan DOĞAN

Health Sciences University

Şişli Hamidiye Etfal Training and

Research Hospital,

Department of Obstetrics and Gynecology,

İstanbul, TURKEY

ozandogan02@ hotmail.com

Copyright $(2018$ by Türkiye Klinikleri

\begin{abstract}
Objective: To assess the effects of outside-in versus inside-out transobturator tapes for stress urinary incontinence on sexual function, quality of life and psychosocial state. Material and Methods: The study was performed on a total of 101 females, who underwent transobturator tape outside-in or inside-out procedures for stress urinary incontinence with no concomitant prolapse repair, between September 2014 and October 2015 at the clinic in Istanbul, and completed a validated quality of life, sexual function, and psychosocial state questionnaires before and after surgery. The scales used for the assessment included the Hospital Anxiety and Depression Scale, Pelvic Organ Prolapse/Urinary Incontinence Sexual Questionnaire-12 and Sexual Quality of Life Questionnaire-Female. Results: The HADS scores showed a statistically significant decrease (an indicator of improvement of anxiety and depression) in the postoperative period in both the groups $(\mathrm{p}<0.05)$. The PISQ-12 scores increased in both the groups in the postoperative period, indicating improvement $(p<0.05)$. The preoperative sexual and partner relationship SQoL-F scores were significantly higher in the inside-out group than in the outside-in group $(\mathrm{p}<0.05)$. Conclusion: The results of this study suggest that transobturator tape procedures for stress urinary incontinence have a positive outcome on female sexual function and quality of life. However, further prospective studies, with more participants, are warranted to support these preliminary findings to be able to compare the impact of transobturator tape outside-in or inside-out routes on female sexual function, quality of life and psychosocial state more precisely.
\end{abstract}

Keywords: Transobturator tape; sexual function; quality of life

tress urinary incontinence (SUI), commonly seen in females, is a pathological condition with a prevalence ranging from $15 \%$ to $55 \%{ }^{1}$ 1 It has been reported to have psychosocial, physical, sexual and emotional effects on a female's well-being, regardless of the type of incontinence. ${ }^{2}$ Sexual dysfunction in women with urinary incontinence is as high as $26-47 \%{ }^{3}$ Urinary incontinence is up to $25 \%$ during sexual intercourse. ${ }^{4}$ Urinary incontinence is often accompanied by psychological disorders like depression and anxiety. ${ }^{5-7}$

Several different surgical procedures have been reported for treating SUI. Transobturator tape (TOT) has been defined as the mainstay in the treatment of female SUI, due to its minimally invasive nature, high success and acceptable complication rates. ${ }^{1}$ TOT, placed in a horizontal plane below the mid-urethra and between the two obturator foramina, creates a 'hammock' that supports the mechanism of urethral closure. Outside-in and inside-out are the two routes of TOT procedures described in the literature. ${ }^{8,9}$ Although both these techniques share the same anatomical approach and 
use the same synthetic materials, yet, the curve, shape of the introducer, way of insertion and the passages are different. TOT is the first choice in surgical treatment; however, the approach may vary depending on the surgeon's preference, probably resulting due to only a few studies comparing the two techniques. ${ }^{10}$ Following surgery, factors that may lead to deterioration of a patient's condition include fibrosis, stenosis, neuronal or vascular damage to the anterior vaginal wall and clitoral region, and placement of artificial material underneath the mid-urethra. ${ }^{11}$

At present, only a limited number of studies have assessed the role of TOT procedure on female quality of life, sexual function, and psychosocial state. ${ }^{12}$ The aim of this study was to compare the postoperative effects of inside-out and outside-in TOT procedures in terms of female sexual function, quality of life and psychosocial state using the Hospital Anxiety and Depression Scale (HADS), Pelvic Organ Prolapse/Urinary Incontinence Sexual Questionnaire-12 (PISQ-12) and Sexual Quality of Life Questionnaire-Female (SQoL-F).

\section{MATERIAL AND METHODS}

This prospective study included 101 females treated with either TOT outside-in or inside-out routes for urodynamically proven SUI, between September 2014 and October 2015 at the author's clinic. Approval was taken by the Local Ethics Committee and the study protocol adhered to the tenets of the Declaration at Helsinki. Written informed consent was obtained from all the participants prior to their enrolment in the study.

The study included females diagnosed with SUI, which was confirmed by urodynamic studies. Patients with detrusor overactivity, pelvic organ prolapse, previous history of malignancy or pelvic radiotherapy, any known neurological disease, previous vaginal surgery, a concomitant gynecological disorder, a history of the psychological disease, patients having a sexually inefficient partner and sexually inactive patients were excluded from the study. Preoperative evaluation included history, physical examination, urinalysis, urogynecological clinical examination, and urodynamic evaluation with cystomanometry. Urodynamic evaluations were performed in accordance with the International Continence Society criteria. ${ }^{13}$ All the patients were asked to complete validated Turkish versions of the HADS, PISQ-12 and SQoL-F preoperatively and at six months postoperatively. ${ }^{14-16}$ The HADS comprises of 14 questions evaluating anxiety and depression of the patient. Each question was scored from 0 to 3 according to the severity of the symptoms (none: 0 , mild: 1 , moderate: 2 and severe: 3 ). The score was evaluated as 0-7 - normal, 8-10- borderline abnormal, and 11-12 - abnormal. Evaluation of sexual function was done using the PISQ-12 questionnaire which consists of 12 questions regarding physical, behavioral-emotive and partnerrelated aspects of sexual function. The total score of this scale ranges from $0-48$, with higher scores indicating better sexual function. The SQoL-F questionnaire was used to evaluate psychosexual feelings, sexual and relationship satisfaction, selfworthlessness and sexual repression parameters. It consists of 18 self-reported questions to measure the characteristic attitudes. The total score ranges between 18 and 108. Each question is scored on a six-point scale, the answers to which may range from 'completely agree' to 'completely disagree'. A higher score reflects a better sexual quality of life. ${ }^{16}$

The patients were randomly allocated to be operated either by the TOT outside-in ( $n=59)$ or inside-out $(n=42)$ route. The assigned treatments were sealed in secure opaque envelopes that were opened just before the surgery. The patient was thus informed about the chosen route just prior to the surgery. A single surgeon performed all the TOT inside-out procedures whereas another surgeon performed all the TOT outside-in procedures at the same tertiary gynecology clinic. The 'outside-in' approach was performed as originally described by Delorme in 2001. ${ }^{8}$ In this technique, the tape is inserted percutaneously, tunneled around the inferior pubic ramus and then guided by the surgeon's finger into the suburethral vaginal incision. The 'inside-out' approach was performed as described by de Leval in 2003 (modified technique) in the reverse route with a 'winged guide' for pro- 
tection of the bladder and the urethra. ${ }^{9}$ All the study participants were followed up for at least six months postoperatively. The assessment at 6month was done by a different clinician who was blinded to the type of surgery performed.

The primary objective was to evaluate the effects of the inside-out or outside-in route on the patients' sexual state using the PISQ-12 parameters. The secondary objective was to compare the effects of both the SUI techniques performed, using the parameters of HADS and SQoL-F. For all patients, the HADS, PISQ-12 and SQoL-F scores were compared before and after surgery, and in addition, comparisons of the data were also made between the females of both the outside-in TOT and insideout TOT groups. All data were recorded and analyzed by a clinician, who was blinded to the group and the surgical technique used.

Statistical analysis was performed with SPSS software (version 22.0 for Windows). Data were expressed as mean, median, standard deviation, percentage, minimum and maximum values. The Kolmogorov-Smirnov test was applied to assess conformity of the data to a normal distribution. The preoperative and postoperative scores were compared using the Paired samples t-test and the Wilcoxon test. A p value of $<0.05$ was considered statistically significant.

\section{RESULTS}

Of the 150 eligible female patients, only 120 met the inclusion criteria and consented to participate while the remaining 30 participants were excluded. These 120 participants were randomly assigned either to the outside-in group or the inside-out group. After randomization, 19 patients were excluded as they either failed to attend the follow-up appointments or failed to submit the questionnaires. In total, 42 females in the inside-out group and 59 in the outside-in group were analyzed. The reasons for pre-randomization and post-randomization exclusion are shown in Figure 1.

Mean age of the patients, BMI and parity were $48.6 \pm 9.4$ years, $25.5 \pm 3.4 \mathrm{~kg} / \mathrm{m}^{2}$, and $2.7 \pm 0.9$, respectively. Out of all the females included, 22\% were premenopausal, $43 \%$ were perimenopausal,

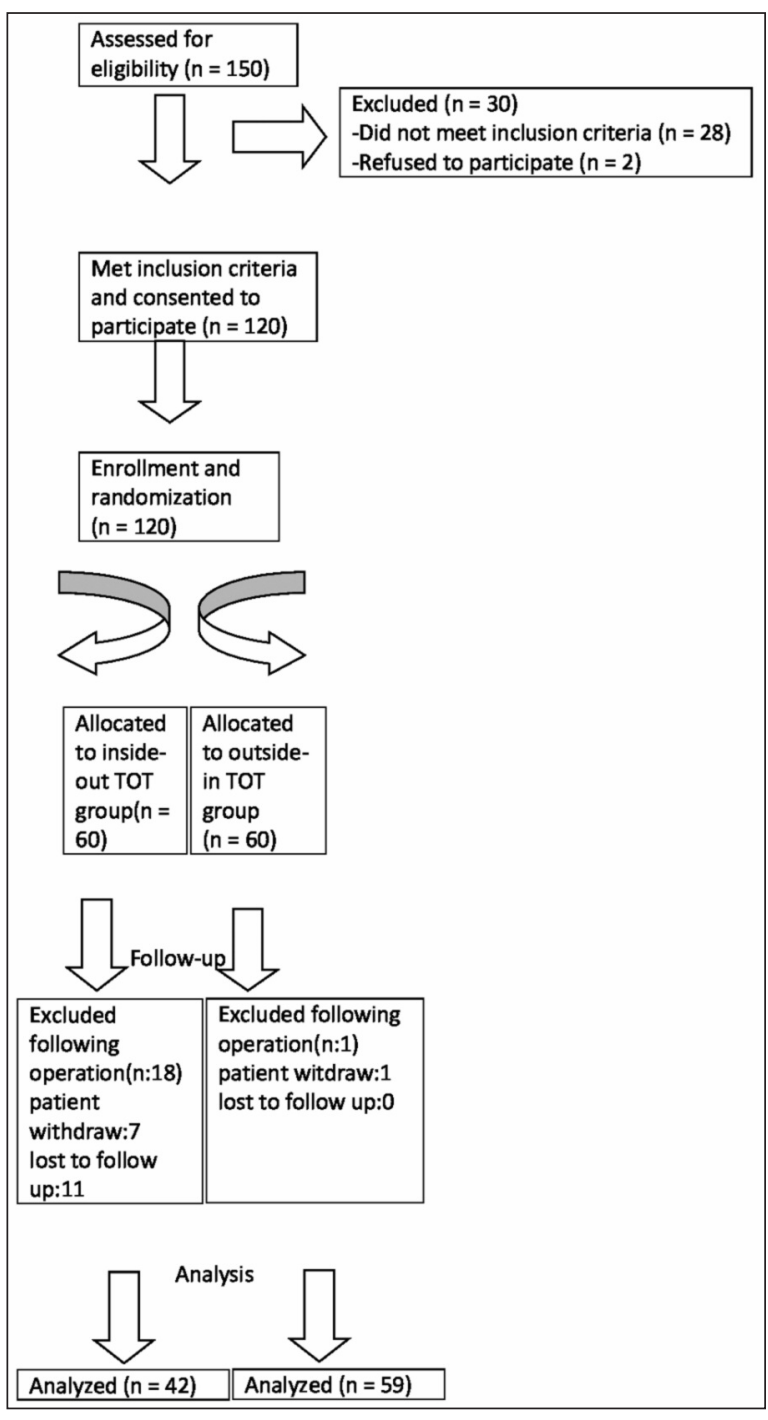

FIGURE 1: Flow diagram of trial recruitment and follow-up

and $36 \%$ were postmenopausal, while $23 \%$ of the patients used hormone replacement therapy. The demographic and clinical characteristics of the patients are presented in Table 1. No significant differences existed between the groups in terms of age, BMI, parity and menopausal status (Table 1).

The pre and postoperative HADS scores, for anxiety and depression, of the two groups are summarized in Table 2. The HADS scores showed a statistically significant decrease (an indicator of improvement of anxiety and depression) in the postoperative period in both the groups $(\mathrm{p}<0.05)$. There was, however, no significant difference in terms of preoperative or postoperative HADS scores $(\mathrm{p}>0.05)$ between the groups. 


\begin{tabular}{|c|c|c|c|c|c|}
\hline & Total $(\mathrm{n}: 101)$ & Outside-in TOT (n:59) & Inside-out TOT (n:42) & $p$ value & OR $(95 \% \mathrm{Cl})$ \\
\hline Age (years)* & $48.6 \pm 9.4$ & $49.3 \pm 9.9$ & $47.7 \pm 8.6$ & 0.403 & -- \\
\hline Parity* & $2.7 \pm 0.9$ & $2.7 \pm 0.8$ & $2.8 \pm 0.9$ & 0.552 & -- \\
\hline BMI $\left(\mathrm{kg} / \mathrm{m}^{2}\right)^{*}$ & $25.5 \pm 3.4$ & $25.3 \pm 3.3$ & $25.7 \pm 3.5$ & 0.629 & -- \\
\hline \multicolumn{6}{|l|}{ Delivery ** } \\
\hline Ceaserean & $13(13)$ & $9(8.9)$ & $4(3.9)$ & 0.397 & $1.7(0.4-5.9)$ \\
\hline Vaginal & $88(87)$ & $50(49.5)$ & $38(37.6)$ & -- & \\
\hline \multicolumn{6}{|c|}{ Menopausal status** } \\
\hline Premenopause & $22(22)$ & $13(13)$ & $9(8.9)$ & 0.666 & $1.0(0.8-1.1)$ \\
\hline Perimenopause & $43(43)$ & $27(27)$ & $16(16)$ & -- & \\
\hline Postmenopause & $36(36)$ & $19(19)$ & $17(17)$ & -- & \\
\hline $\mathrm{HRT}^{\star \star *}$ & $23(23)$ & 17 (17) & $6(5.9)$ & 0.086 & $2.0(0.8-4.6)$ \\
\hline
\end{tabular}

Data are expressed as mean \pm standard deviation ${ }^{\star}$ or $n(\%)^{\star *}$

HRT: Hormone replacement therapy.

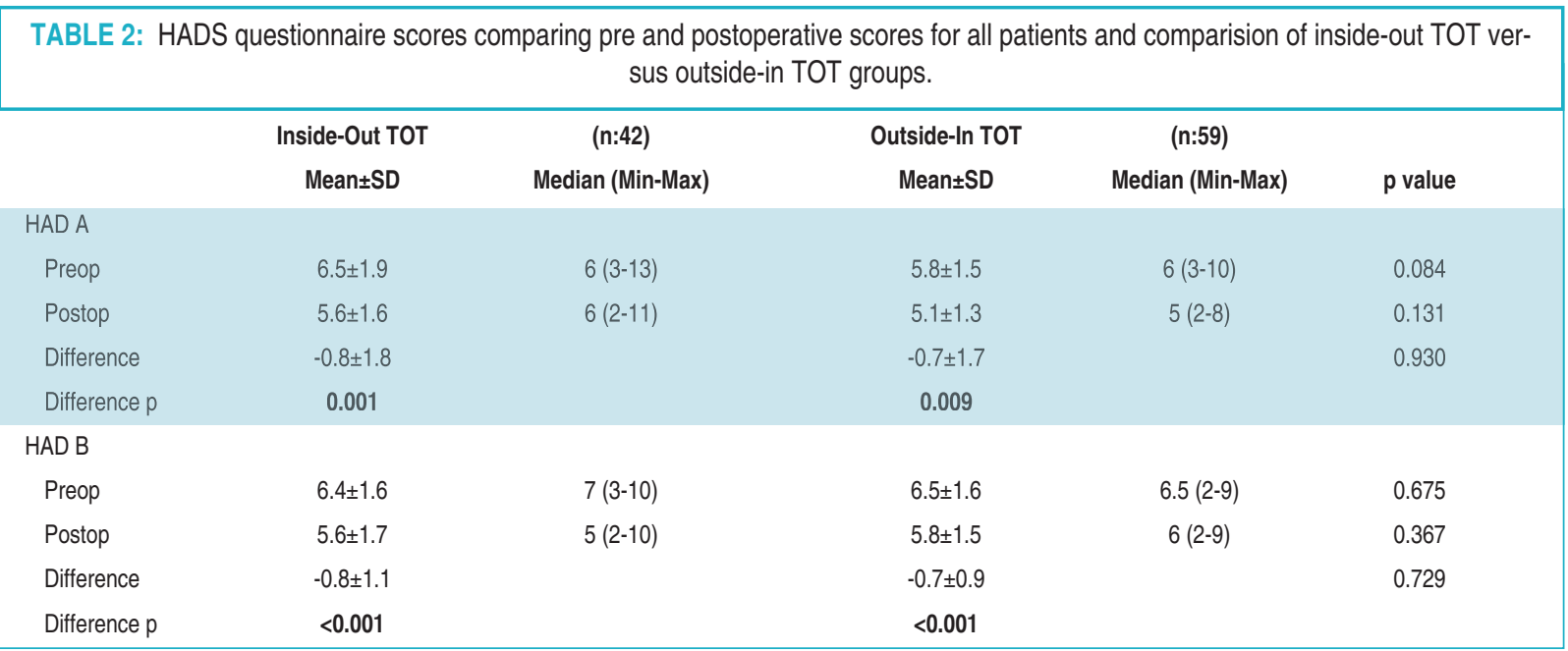

HADS: Hospital Anxiety and Depression Scale.

The preoperative and postoperative PISQ-12 scores for emotional, physical, behavioral and partner relationship are summarized in Table 3. No significant difference in the preoperative PISQ-12 score was found between the groups $(p>0.05)$. In both the groups, it was observed that PISQ-12 scores increased in the postoperative period, thereby indicating improvement $(\mathrm{p}<0.05)$. The postoperative emotional-behavioral scores increased more in the inside-out group than in the outside-in group and the difference was observed to be statistically significant $(\mathrm{p}<0.05)$.

Results of the SQoL-F questionnaire for psychosexual feelings, sexual and relationship satisfaction, self-worthlessness and sexual depression are presented in Table 4 . In the preoperative period, the psychosexual feelings, sexual repression and total SQoL-F parameter scores were similar in both the groups. The preoperative sexual and partner relationship SQoL-F scores were significantly higher in the inside-out group than in the outside-in group $(\mathrm{p}<0.05)$. The preoperative self-worthlessness SQoLF scores were statistically higher in the outside-in group than in the inside-out group $(\mathrm{p}<0.05)$. There was no significant difference between the median improvements among the two groups.

\section{DISCUSSION}

The results of this study demonstrate that emotional-behavioral and physical scores showed a sig- 


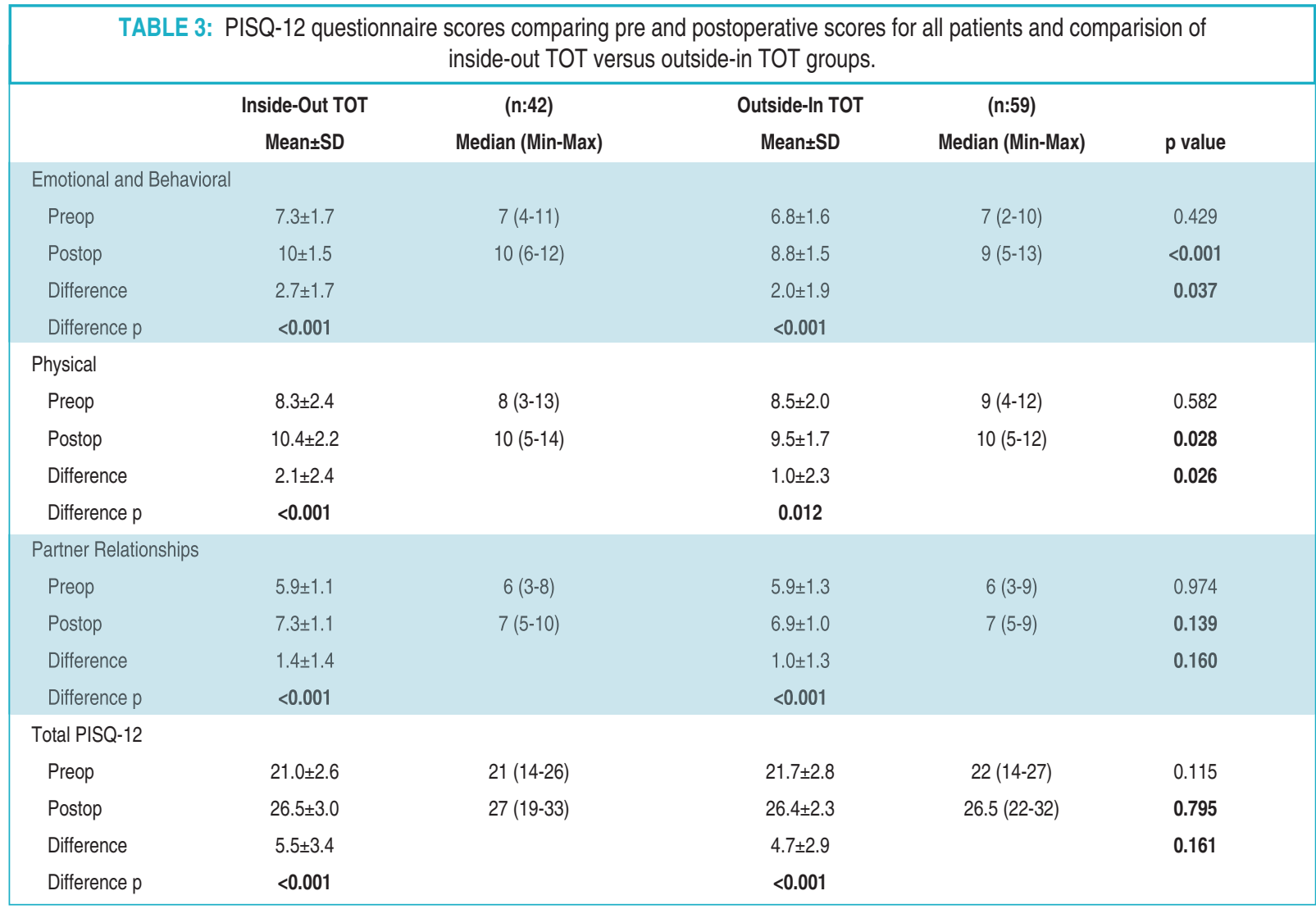

PISQ-12: Pelvic Organ Prolapse/Urinary Incontinence Sexual Questionnaire-12.

nificant improvement postoperatively, in the inside-out TOT group in comparison to the outsidein TOT group, as assessed by the PIS-Q12 scale. Furthermore, all the parameters showed a significant improvement after the SUI surgery.

Female sexual dysfunction is described as a decrease in the frequency of coitus, anorgasmia, dyspareunia, low desire and arousal difficulty in comparison to the healthy female population, and is also associated with lower urinary tract symptoms, urinary incontinence and pelvic organ prolapse. ${ }^{17}$ SUI has a negative effect on female sexual function because it leads to embarrassment, psychological distress, or simple distress caused by urine leakage during sexual intercourse, in particular. ${ }^{17-19}$ Therefore, proper treatment of SUI and surgical success are overwhelmingly important for the improvement of psychosocial and sexual function caused by the incontinence. TOT has been prescribed for SUI since it is minimally invasive, and has a high success rate and acceptable compli- cation rates. Two techniques of TOT have been introduced, the inside-out TOT approach, as described by de Leval in 2003 and the outside-in TOT approach, as described by Delorme in 2001. Recent studies have reported that both the outside-in and inside-out approaches of TOT procedure are safe, effective and have a similar cure and complication rates in SUI management. ${ }^{20}$

In the present study, it was deliberated that patients complaining of urinary incontinence may have depression-anxiety and that incontinence surgery may result in mood improvement of the patients. Therefore, the HADS questionnaire was applied in the preoperative and the postoperative periods in both the groups. As expected, the postoperative HADS scores were observed to be lower (an indicator of improvement of anxiety and depression) in both the groups. Nan et al. also found improved rates of satisfaction after treatment in patients with urinary incontinence and observed significantly lower anxiety symptom scores. ${ }^{21}$ 


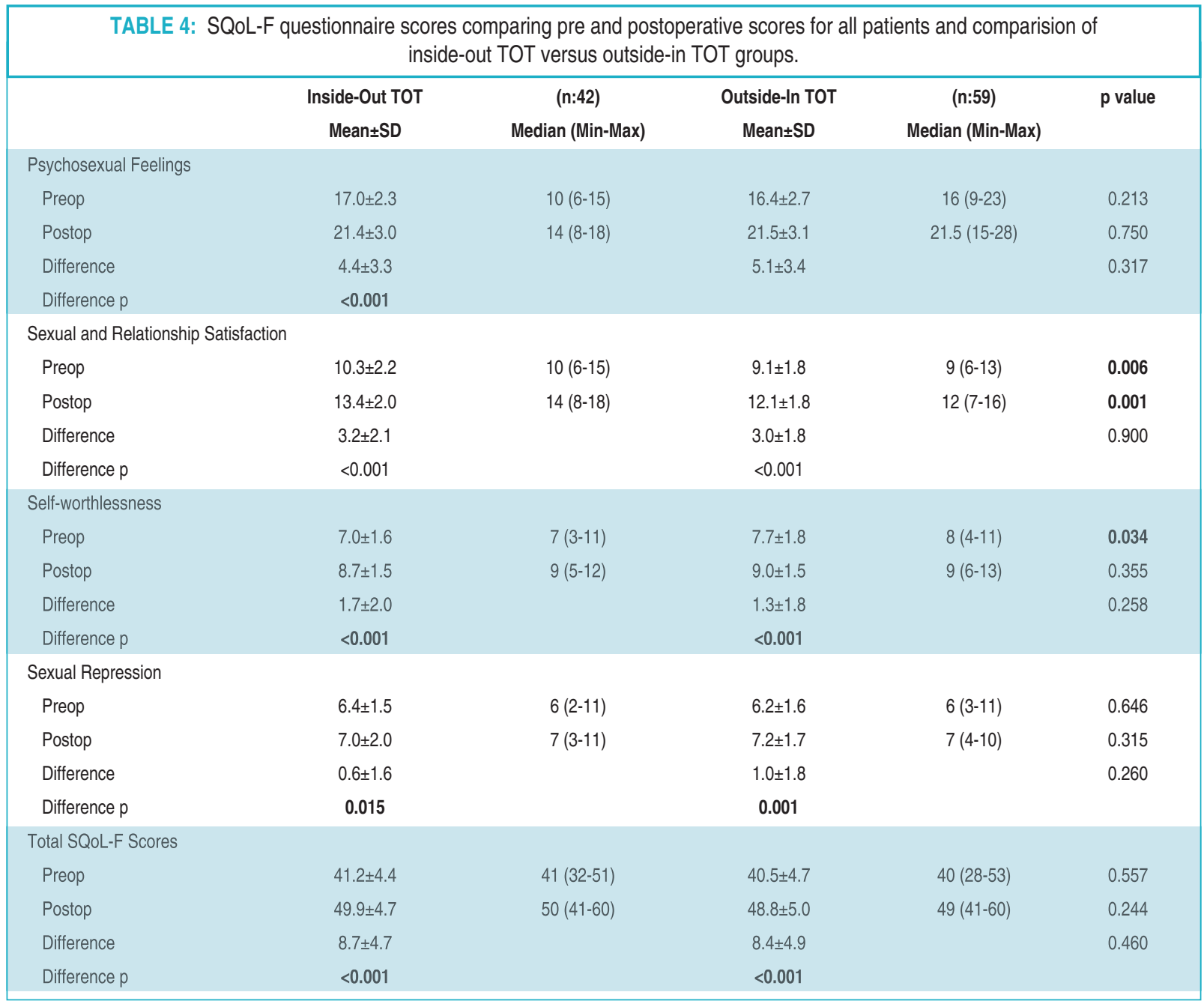

SQoL-F: Sexual Quality of Life Questionnaire-Female.

The PISQ-12 questionnaire focuses on female sexual functions including desire, arousal, lubrication, orgasm, satisfaction, and pain. In the present study, PISQ-12 was used as a condition-specific questionnaire obtained before and six months after the TOT surgery. It was employed to assess the sexual function in females with urinary incontinence. This scale has been found to be reliable, valid and responsive, and at the same time displays good internal consistency. The SQoL-F questionnaire focuses on the quality of life such as psychosexual feelings, sexual and relationship satisfaction, self-worthlessness and sexual depression. All the parameters showed significant improvement after the SUI surgery, with no significant differences between the two groups except that in the emotional-behavioral and physical scores. The statistical increase in the emotional-behavioral and physical scores was found to be more in the inside-out group than in the outside-in group. Simsek et al. reported similar findings while Pace et al. also observed that the TOT procedure led to a significant improvement in the sexual function and quality of life. ${ }^{22,23} \mathrm{In}$ contrast to the present study, Cayan et al. reported that sexual functions including desire, arousal, lubrication, orgasm and satisfaction scores decreased significantly in all females in the postoperative stage compared to that in the preoperative stage. ${ }^{17}$ Studies conducted by Bekker et al. and Berthier et al. reported that improvement in coital incontinence resulted in improvement in sexual func- 
tion in females successfully treated with incontinence surgery. ${ }^{4,24}$ Complications of TOT surgery, however, may lead to a deterioration of the sexual functions. In the current study, the improvement in postoperative scores may be due to the selection of patients including those who benefitted from surgical treatment, patients with no postoperative complications and patients having no postoperative incontinence.

Since $30-50 \%$ of the females suffer from sexual dysfunction, most of the recent research focuses on the problems related to urological and gynecological surgery. ${ }^{19,25,26}$ Sexual functions (congestion, tenting, sexual arousal and lubrication, as well as mucous secretion) may deteriorate as a result of vaginal surgery because of fibrosis, stenosis, erosion of the sling and partner discomfort. The anterior vaginal wall has a rich neurovascular supply and incision of the anterior vaginal wall for anti-incontinence surgery may damage the vascular and neuronal tissue of the vagina. ${ }^{4,22,27}$ A statistically significant increase in the postoperative emotional-behavioral and physical scores of females was observed in the inside-out TOT group as compared to that in the outside-in TOT group. The findings of this study support the view that the small incision and minimally invasive (dissection area) approach of the inside-out TOT procedure causes minimal damage to the anterior vaginal wall.

One of the limitations of the study is the lack of data related to other factors like education, race, religion, culture, social events, history of sexual abuse or sexually transmitted disease, chronic diseases and cigarette smoking, all of which may also affect the sexual functions. Furthermore, patients with any complications were excluded from the study and therefore could not be evaluated for the effects of the surgery on sexual function. The exclusion of a different number of patients from each of the two groups during the follow-up period is another limitation of the study.

\section{CONCLUSION}

It is thus clear that urinary incontinence has a negative effect on sexual functions, quality of life and psychosocial state of the patient. The results of this study show that both techniques of the TOT procedure (inside-out and outside-in) result in statistically significant improvements in sexual functions, psychosocial state and quality of life after surgery. In addition, the postoperative physical and behavioral-emotional scores of the PISQ-12 were determined to have increased more in the inside-out group than in the outside-in group. Further prospective randomized studies with more participants are warranted to support these preliminary findings in order to compare the quality of life and sexual function outcomes of the inside-out and outside-in TOT procedures.

\section{Source of Finance}

During this study, no financial or spiritual support was received neither from any pharmaceutical company that has a direct connection with the research subject, nor from a company that provides or produces medical instruments and materials which may negatively affect the evaluation process of this study.

\section{Conflict of Interest}

No conflicts of interest between the authors and / or family members of the scientific and medical committee members or members of the potential conflicts of interest, counseling, expertise, working conditions, share holding and similar situations in any firm.

\section{Authorship Contributions}

Idea/Concept: Bülent Arıcı, Osman Temizkan, Çiğdem Pulatoğlu, Ozan Doğan, Faruk Abike, Osman Aşıcıoğlu; Design: Bülent Arıcı, Çiğdem Pulatoğlu; Control/Supervision: Ozan Doğan, Osman Aşıcıoğlu, Faruk Abike, Osman Temizkan; Data Collection and/or Processing: Bülent Arıcı, Çiğdem Pulatoğlu, Osman Temizkan, Ozan Doğan, Osman Aşıcıoğlu, Faruk Abike; Analysis and/or Interpretation: Osman Aşıcıoğlu, Çiğdem Pulatoğlu, Bülent Arıc1; Literature Review: Ozan Doğan, Faruk Abike; Writing the Article: Ozan Doğan, Çiğdem Pulatoğlu; Critical Review: Ozan Doğan, Çiğdem Pulatoğlu; References and Fundings: Osman Temizkan, Osman Aşıcıoğlu. 
1. Norton $P$, Brubaker L. Urinary incontinence in women. Lancet 2006;367:57-67.

2. Yip SK, Chan A, Pang S, et al: The impact of urodynamic stress incontinence and detrusor overactivity on marital relationship and sexual function. Am J Obstet Gynecol 188: 12441248, 2003.

3. Ko Y, Lin S-J, Salmon W, Bron MS. The impact of urinary incontinence on quality of life of the elderly. Am J Manag Care 2005;11:10311.

4. Bekker M, Beck J, Putter H, Venema P, Lycklama à Nijeholt A, Pelger R, Elzevier H. Sexual function improvement following surgery for stress incontinence: the relevance of coital incontinence. J Sex Med 2009;6(11):3208-13.

5. Sentilhes L, Berthier A, Caremel R, Loisel C, Marpeau L, Grise P. Sexual function after transobturator tape procedure for stress urinary incontinence. Urology 2008;71(6):1074-9.

6. El-Enen MA, Ragb M, El Gamasy Ael-N, ElAshry O, El-Sharaby M, Elbadawy A, Fayed N. Sexual function among women with stress incontinence after using transobturator vaginal tape, and its correlation with patient's expectations. BJU Int 2009;104(8):1118-23.

7. Asoglu MR, Selcuk S, Cam C, Cogendez E, Karateke A. Effects of urinary incontinence subtypes on women's quality of life (including sexual life) and psychosocial state. Eur J Obstet Gynecol Reprod Biol 2014;176:187-90.

8. Delorme E. Transobturator urethral suspension: mini-invasive procedure in the treatment of stress urinary incontinence in women. Prog Urol 2001;11:1306-13

9. De Leval J. Novel surgical technique for treatment of female stress urinary incontinence: transobturator vaginal tape inside-out. Eur Urol 2003;44:724-30.

10. Abdel-Fattah M, Ramsay I. Transobturator tension free vaginal tapes: are they the way

\section{REFERENCES}

forward in the surgical treatment of urodynamic stress incontinence? Int J Surg 2007;5:3-10

11. Tunuguntla HS, and Gousse AE: Female sexual dysfunction following vaginal surgery: a review. J Urol 175: 439-446, 2006.

12. Murphy M, van Raalte $H$, Mercurio E, et al: Incontinence-related quality of life and sexual function following the tension-free vaginal tape versus the "inside-out" tension-free vaginal tape obturator. Int Urogynecol J Pelvic Floor Dysfunct 19: 481-487, 2008.

13. Gordon D, Gold RS, Pauzner D, Lessing JB, Groutz A. Combined genitouurinary prolapsed repair and prophylactic tension-free vaginal tape in women with severe prolapsed and occult stress urinary incontinence: preliminary results. Urology 2001;58:547-550.

14. Aydemir Ö, Güvenir T, Küey L, Kültür S. The reliability and validity of Turkish form of Hospital Anxiety and Depression Scale. Journal of Turkish Psychiatry 1997;8(4): 280-7.

15. Cam C, Sancak P, Karahan N, Sancak A, Celik C, Karateke A.Validation of the short form of the pelvic organ prolapse/urinary incontinence sexual questionnaire (PISQ-12)in a Turkish population.Eur J Obstet Gynecol Reprod Biol 2009;146:104-7.

16. Tugut N, Golbasi Z. A validity and reliability study of Turkish version of the Sexual Quality of Life Questionnaire-Female. Cumhuriyet Med J 2010; 32:172-180.

17. Cayan F, Dilek S, Akbay E, Cayan S. Sexual function after surgery for stress urinary incontinence: vaginal sling versus Burch colposuspension. Arch Gynecol Obstet 2008;277(1): 31-6.

18. Glavind K, Tetsche MS. Sexual function in women before and after suburethral sling operation for stress urinary incontinence: a retrospective questionnaire study. Acta Obstet Gynecol Scand 2004;83(10):965-8.
19. Elzevier HW, Putter H, Delaere KP, Venema $\mathrm{PL}$, Lycklama à Nijeholt AA, Pelger RC. Female sexual function after surgery for stress urinary incontinence: transobturator suburethral tape vs. tension-free vaginal tape obturator. J Sex Med 2008;5(2):400-6.

20. Cheung RYK, Chan SSC. Inside-out versus outside-in transobturator tension-free vagina tape: A 5-year prospective comparative study. Int J Urol 2014;21:74-80.

21. Nan L, Fones SL, Thumboo J, Li SC. Factors influencing health-related quality of life of Asians with anxiety disorders in Singapore. Qual Life Res 2004:13:557-65.

22. Simsek A, Ozgor F, Yuksel B, Kucuktopcu O, Kirecci SL, Toptas M, et al. Female sexual function after transobturator-tape in women with urodynamic stres urinary incontinence. Springerplus 2014;30;3:570

23. Pace $G$, Vicentini $C$. Female sexual function evaluation of the tension-free vaginal tape (TVT) and transobturator suburethral tape (TOT) incontinence surgery: results of a prospective study. J Sex Med 2008;5:387-93.

24. Berthier A, Sentilhes L, Taibi S, Loisel C, Grise $P$, Marpeau L. Sexual function in women following the transvaginal tension-free tape procedure for incontinence. Int J Gynaecol Obstet 2008;102:105-9.

25. Ghielmetti T, Kuhn P, Dreher EF, Kuhn A. Gynaecological operations: Do they improve sexual life? Eur J Obstet Gynecol Reprod Biol 2006:129:104-10.

26. Caruso S, Rugolo S, Bandiera S, Mirabella D, Cavallaro A, Cianci A. Clitoral blood flow changes after surgery for stress urinary incontinence: pilot study on TVT Versus TOT procedures. Urology 2007;70(3):554-7.

27. Katz A. Sexuality after hysterectomy: a review of the literature and discussion of nurses' role. J Adv Nurs 2003; 42:297-303. 